\title{
The Gravitational Fields of J.M Coetzee's Fiction
}

\author{
Nabit ELGARHI, Ph.D. Candidate \\ Ibn Zohr University - Agadir, Morocco \\ elgarhirealc@gmail.com
}

DOI: http://doi.org/ 10.36892/ijlls.v3i3.650

\begin{tabular}{|c|c|}
\hline Received: & \multirow{9}{*}{$\begin{array}{l}\text { Abstract } \\
\text { The novels of J.M. Coetzee, South African novelist, have always been a } \\
\text { source of inspiration for both readers and critics. A distinctive feature } \\
\text { of his writing is the ability to converse with a wide range of disciplines } \\
\text { amongst which is the scientific field stands distinguishingly appealing. } \\
\text { This paper will explore the use of cosmology terminology to see its } \\
\text { underpinnings in J.M Coetzee's fiction as well as in Derek Attridge's } \\
\text { insightful criticisms. The gravitational velocity of J.M Coetzee's fiction } \\
\text { stems from his text's singularity. Singularity remains Coetzee's } \\
\text { hallmark to engage with ethics and politics of otherness. The } \\
\text { deconstruction of the simplistic and the normative comprehensions of } \\
\text { post-apartheid establishes Coetzee's singularity as his ethical defense } \\
\text { of the singularity of literature on a large scale. }\end{array}$} \\
\hline $15 / 07 / 2021$ & \\
\hline Acce & \\
\hline $18 / 09 / 2021$ & \\
\hline Keywords: & \\
\hline Singularity, & \\
\hline Aesthetics, Ethics, & \\
\hline & \\
\hline & \\
\hline
\end{tabular}

\section{INTRODUCTION}

Metaphors play a crucial role in the production of knowledge as they permit people to concretize the relations between abstract concepts and everyday experiences. The scientific language is not an exception because it heavily relies on the pragmatic use of literary metaphors to constrain scientific reasoning and to grant the findings of science acceptance among the masses. Scientists, scholars and philosophers thoughtfully consider the importance of metaphors in communicating hard ideas. Despite their limits and the possible problems resulting from their misunderstanding, metaphors help in the development of hypotheses and in the interpretation of results. On the other hand, the language of literature, highly metaphorical by nature, sometimes resorts to scientific terminology to trigger other associations so to enlarge the scope of meaning and interpretation. Metaphors commute between the scientific and the literary worlds to carry connotations and to guarantee the flexibility of interdisciplinary fields of human knowledge. Arguably, it is the objective of this paper to examine the generative potential of metaphorical concepts such as black holes and singularity in their relation to our understanding of J.M Coetzee's ethical defense of the singularity of literature.

\section{The Singularities of Fiction and Black Holes}

Was it a pure coincidence that Jacques Derrida applied the concept of "singularity" to his anatomy of literature and otherness? Historically speaking, and prior to the emergence of Derrida as a prominent scholar, "the concept of singularity [was] introduced by [Sir Roger] Penrose and later on expanded by Hawking." The unusual uses of terms from other fields of

\footnotetext{
${ }^{1}$ Prakash, N. (2003). Mathematical Perspectives on Theoretical Physics: A Journey from Black Holes
} 
human sciences were no breaking news when related to the thinking of Jacques Derrida. In other words, Derrida resorts to a rich repertoire of vocabulary by which he made his philosophy accessible and possible to grapple with. Terms such as "pharmakon", "hymn", and "singularity", to name but a few, are examples of his meticulously calculated sporting with languages notably Greek language. In the light of his multidisciplinary fed erudition, I venture to claim that Jacques Derrida, maybe because of his fascination with the beauty of physics, made use of the concept singularity to instill it within his own exuberant philosophical investigations.

Likewise, Derek Attridge, one of J.M Coetzee's most insightful critics, makes use of the term of "singularity" out of his fascination with Derrida's deployment of the term. Attridge makes his intimations with Derrida's style of thinking explicit in his thorough readings of J.M Coetzee's novels. Surprisingly, the use of "singularity" itself has undergone the Derridean process of "difference" when applied to literature in general and to J.M Coetzee in particular. The peculiarities of J.M Coetzee's fiction draw the attention of Attridge whose book The Singularity of Literature has become a major reference in literary criticism in recent years.

The common use of "singularity" within the scientific field is associated with the exciting world of physics. Singularity along with "event horizon" and "gravitational fields" become defining concepts of the theory of black holes. However, as shall be subsequently demonstrated, the cosmic singularity of the black hole casts its own characteristics upon the literary text. In this paper, the main thesis is to examine that both the literary text, the novel more precisely, and the black hole share the same similarities in a way that is tellingly defying to the measurements of scientific equations and literary approaches of criticism. J.M Coetzee is our case-study in this article because his writings reflex the premises of Jacques Derrida and Derek Attridge's arguments regarding the singularity of literature which feeds into the singularity of otherness.

The black hole and the literary text almost have the same common features and qualities as they both have a very idiosyncratically distinctive "singularity". Both worlds, the literary and the cosmic, are analogous in the sense that lots of theories have been produced about them to uncover the incommensurable essence being at the heart of each world. It is by way of analogy that some fiction writers and literary critics make use of cosmology terms to label the characteristics of fiction writing in the same way physicists and scientists use hardto-understand mathematical language to explain the universe. That is, language from both fields mutually inspiringly feeds into each other to expand their own limits of denotation. For instance, André Brink, the South African writer and critic, was the first to allude to the similarity between the novel and the black hole due to the seemingly shared features and characteristics. In The Novel: Language and Narrative from Cervantes to Calvino, André Brink speaks about the novel as a black hole in the sense that it is "invisible in itself, perceived only through its effect on contiguous bodies, into which everything entering its sphere of gravity is sucked; existence collapsed into itself, dark and unfathomable, resplendent and miraculous." ${ }^{2}$ Interestingly enough, Derek Attridge, has almost borrowed the same diction governing the theory of the black hole to make it applicable in his argumentation for the singularity of literature and eventually the singularity of J.M Coetzee.

Let us begin first by simplifying our understanding of the hard theoretical concepts that generated of the "Black Hole Theory." I will briefly focus on the main terms used to explain such a cosmic phenomenon. First, it should be mentioned that the term "'black hole" was first mentioned in print in an article by Ann Ewing in 1964, reporting on a symposium

to Superstrings. World Scientific Publishing Company, p. 429.

${ }^{2}$ Brink, A. (1998). The Novel: Language and Narrative from Cervantes to Calvino. Macmillan International Higher Education, p. 286. 
held in Texas in 1963, although she never mentioned who coined the expression." 3 However, in the introduction to Black hole physics: Basic Concepts and New Developments (2012), the term " "black hole' was introduced by Wheeler in 1967 although the theoretical study of these object has a quite long history." 4 Nevertheless, what is of more significance for us is that a "black hole is a region of space where the force of gravity is so strong that nothing, not even light, can travel fast enough to escape from its interior." 5 This very fact proves that an exact history of when the term is scientifically used remains controversial and uncertain.

Second, "singularity", as unanimously defined by physicists and cosmologists, is the basic structure and the "building block" of any black hole. A major characteristic of this region of space is its containment of a hugely "dense energy" that forms all the mass of the black hole. Singularity is exactly that "region of space where the density of matter, or the curvature of space-time becomes infinite, and the concepts of time and space cease to have any meaning." 6 This is why, this term seems appealing to Derrida and Attridge for its appalling attractiveness.

Third, the "event horizon" or the invisible boundary of the black hole is the edge whereby the high velocity of its "gravitational field" becomes as inescapable as the velocity of gravity. ${ }^{7}$ Because it is wrapped in its own mystery, nothing can be communicated outside of the black hole. ${ }^{8}$ It is not just a black hole but it is rather a black box full of secrets that are unlikely to be revealed at all cost and in one go. Out of scientific shortsightedness, I am not a specialist in the field to explicate such hard terms in laymen's terms. They are brain damaging concepts that only experts can fully relate to.

Still, over the last centuries of Western literary history, the ongoing fashion of inventing literary theories has become inadequate to address major questions of whether the artistic work should surrender to the tyranny of a certain specific mode of thought. This necessitates to understand the reason why such literary theories [alongside their inability to provide a one general unanimous analytical response to the literary product] are either exclusionary, ${ }^{9}$ or are not able, despite their insightfulness, to be valid and useful for every text and context. That is to say, there is a failure to come up with a unified theory that would resolve the contradictions and explain everything. It is the same current failure shared by both cosmologists and fiction critics to invent a "theory of everything"10. The search for a unified theory and a solid all-encompassing equation that can explain everything was one of Stephen Hawking's and other physicists' greatest scientific aspirations and one of the most challenging tasks facing theoretical physics and mathematics up to day.

Any use of the metaphorical concept of the "black hole" has only a methodological purpose to argue that the fictional work of J.M Coetzee is itself a black hole with an 'event horizon' that sucks all seemingly incisive literary approaches. In every literary work and novel, there is a "singularity" in the same way "singularity" resides at the center of every

${ }^{3}$ Blundell, K. (2015). Black Holes: A Very Short Introduction. Oxford University Press, p. 5.

${ }^{4}$ Frolov, V., \& Novikov, I. (2012). Black Hole Physics: Basic Concepts and New Developments

(Vol. 96). Springer Science \& Business Media, p.4.

${ }^{5}$ Blundell, K. (2015). Black Holes: A Very Short Introduction. Oxford University Press, p. 5.

${ }^{6}$ https://www.physicsoftheuniverse.com/topics_blackholes_singularities.html. Last visited: 7th of June 2018.

${ }^{7}$ Ibid.

8 Ibid.

9 By exclusionary, I mean when a certain literary theory is applied to a literary text, it usually intends to reject the presence of another theory and of anything different from their core philosophy/ ideology.

${ }^{10}$ A theory of everything, final theory, ultimate theory, or master theory is a hypothetical single, allencompassing, coherent theoretical framework of physics that fully explains and links together all physical aspects of the universe. Finding a TOE is one of the major unsolved problems in physics.

Source: https://en.wikipedia.org/wiki/Theory of everything Last visited 23 August 2018. 
black hole. The novel and the black hole in space are analogous in the sense that each of them possesses a huge gravitational "event horizon" and a "singularity" that suspends and extends the existence of each of these phenomena in unique ways. If the "Big Bang" is considered as an unprecedented and an unpredicted event, the novel is also an unprecedented "event" because like the Big Bang, the novel "ha[s] a beginning at a singularity" 11 in time, too. Here, I would dare to take on Brink's metaphor of the black hole to talk about the singularity of the novel and its gravitational features with the aim of demonstrating how the literary oeuvre is similar to the black hole in its complexity. The totalitarian exclusionary aspects of literary theories are considered to be their innate hubris because "anything that falls inside the event horizon moves down towards the singularity. It merges into the singularity, which is $[\ldots . .$. infinitely dense" ${ }^{12}$. In fact, no critic or scholar knows exactly "what laws apply at these immense densities, so we can't describe what the conditions are like. We literally have a "black hole" in our knowledge."13

Cosmologists' attempts to come up with a theory of everything might have inspired many literary critics, basing themselves on the interdisciplinary nature of human knowledge to wonder if there is a possibility for literary critics to invent an all-covering and unanimously accepted theory of literature. In other words, is there a literary theory that is able to tackle a certain work of art from a holistic multi-dimensionally perspective? But prior to this, Stephen Hawking's scientific works which were, later on, transformed into literary beauty which was ultimately crafted in his bestseller The Theory of Everything (2016), and which was published under the all-encompassing banner of "literature" has instigated the reader's curiosity to step into the field of cosmic science to probe into the singularity of literature. Of course, "if you start probing... [you] must learn a whole language first" ${ }^{14}$ because stepping into a new field of research requires a new jargon to keep track of the ideas expressed in that field's specific diction. It is not my objective to marry some aspects of literature to some other features already existing in science so as to argue that Derek Attridge in his book The Singularity of Literature has coined not just the term "singularity" but maybe the idea of the "black hole" in its entirety to support his thesis of the singularity of literature and the ethics of reading. That being said, I will use the term "singularity" similarly as Derek Attridge used it, but my train of thought will differently take on another truck, and that will arrive to the same conclusion of Attridge's. The conclusion that says the literary text is a unique innovative event and which is wrapped in a singularity similar to the one cosmology physicists argue for. It is also the same singularity that J.M Coetzee has wrestled with in his fiction and works of criticism because according to Stephen Watson, "Coetzee's work will continue to elude whatever critical net might be used to pin it down"15

If by ethics, Derek Attridge means the moral obligations towards otherness (Attridge here is to a great extent influenced by Emmanuel Levinas) when reading a text of literature, what is, then, the role of aesthetics? Is not there an amalgamation of both aesthetics and ethics to create that dense point of "singularity" which holds the secret essence of any literary production? The density of the black hole is previously prepared for by the "event horizon" which is, I think, the aesthetic property of the literary written text. Behind this aestheticism

${ }^{11}$ Hawking Hawking, S. W. (1993). Hawking on the Big Bang and Black Holes (Vol. 8). World Scientific, p.2.

12 Maran, S. P. (2017). Astronomy for Dummies. John Wiley \& Sons, p. 271.

${ }^{13}$ Ibid., p. 222

${ }^{14}$ Brink, A. (2011). Dry White Season. Random House, p.161.

${ }^{15}$ Huggan, G., \& Watson, S. (Eds.). (1996). Critical Perspectives on JM Coetzee. Springer, p. 6. 


\section{The Gravitational Fields of J.M Coetzee's Fiction}

that I venture to name it "event horizon" because it hides what lies beneath, there lies a certain singularity that occurs uniquely and differentiatingly at every act of reading. It should not be held at this point that there is an antagonism between the ethical and the aesthetic as much as there is an aim to explore the idea that the aesthetic paves the way for the ethical in order the literary text be accountable for as a whole. To put it differently, the ethical responsibility of both writer and reader is built only upon the aesthetic essence and frame of the act of writing. It is not a kind of favoritism of one aspect over the other. Rather, the aesthetic and the ethical are like the oxen pair tied by the same yoke which is the same reverberating reality when it comes to the inseparability of the "event horizon" and "the singularity" of the black hole.

Derek Attridge's argument of the singularity of literature is based on much of the philosophical investigations of Jacques Derrida who has the conviction that the literary written text will always remain as an unfathomable and an impenetrable barren land. Accordingly, Derek Attridge proclaims that the singularity of literature emanates from the trinity of innovation or invention, the uniqueness or singularity of the artwork, and the concept of otherness or alterity that basically underlies the cornerstones of his triadic pattern. A prototype of this singularity of literature for Attridge is the fictional works of the South African writer J.M Coetzee who stoically and ceaselessly fights off the various attempts of mis/appropriation and ill-intentioned handling of the literary work. J.M Coetzee repeatedly avows his challenge and strong will to radically reinvent the conventional criticisms as he creates his own "liberating" discourse of criticism. He is aware of the fact that it is:

a mark of all critical activity to try to swallow one kind of discourse into another kind of discourse. For example, in academic criticism, to swallow literature into a certain kind of academic discourse. And many of the unformed resistances...that people have towards the whole academic activity seem to me connected with a sense that one discourse is swallowing another, when one may not want that. ${ }^{16}$

Here, Coetzee is highly aware of the problems that might result from the forceful marriage of the literary text and theories outside of it. He shuns the intentions to make the text says what it does not intend. In Doubling the Point, Coetzee wonders what criticism is or "[w] ever be, but either a betrayal (the usual case) or an overpowering (the rarer case) of its object? How often is there an equal marriage?" (DP, p. 61) Coetzee strategically moves in a chesslike game throughout all his writings, in a pre-emptive war-like writing method, to disarm and to disempower the critics of their pre-established frames by which the text will be approached and appropriated. Teresa Dovey has argued that Coetzee "wittingly inhabits prior modes of discourse in order to deconstruct them from within," and it is "in this sense the novels may be described as postmodern allegories, which undermine the authority of the appropriated discourses"17

J.M Coetzee seems to differentiate between two kinds of criticism; while he is deriding the dominance and governance of literary criticisms over his texts, he is embracing a unique way of writing in which he is "developing a general discourse of cultural criticism about the nature and value of modernity"18 Coetzee favours a novel of "rivalry" at the expense of any "supplementarity" because this "supplementarity" emanates from and feeds into obsolete antagonistic realistic views of the world that entice the reader's responses in the

${ }^{16}$ Coetzee, J. M. (1980). "Grubbing for the Ideological Implications: A Clash (More or Less) with JM Coetzee." Interview by Alan Thorold and Richard Wicksteed, 3-5.

17 Dovey, T. (1998). JM Coetzee: Writing in the Middle Voice. Critical Essays on JM Coetzee, p.19.

${ }^{18}$ Hayes, P. (2010). JM Coetzee and the Novel: Writing and Politics After Beckett. Oxford University Press, p. 224. 
illusion of truth and sameness. Using a precise scientific metaphorical language, Coetzee asserts that "[i]n times of intense ideological pressure like the present, when the space in which the novel and history normally coexist like two cows on the same pasture, each minding its own business, is squeezed to almost nothing, the novel, it seems to me, has only two options: supplementarity or rivalry." ${ }^{19}$ Coetzee is obsessed by the futility of realism as per se for its inability to envision the human condition in its futuristically incomplete build up. Coetzee's writing is "designed to refuse this simplification, and to open up a more productive line of cultural criticism - one better fitted to navigating the complex terrain of political modernity." ${ }^{20}$ Coetzee goes on to argue that "anti-illusionism is [...] only a marking of time, a phase of recuperation, in the history of the novel. The question is, what next?" (DP, p. 27).

Supplementarity or conformity do not do justice to writing in the modern era of human cultural history as much as it stifles inventiveness, and renders writing modeled in the same repetitive molding modeling of "vraisemblance" and copy-pasting of human experiences as is the case of journalistic or documentary writing. The outcome is a kind of writing that should be preferably placed on the shelves of archived historic recordings that are fraught with abominable stories of politics, apartheid discontents, and other world issues of race, identity, and cultural tensions. Coetzee follows the steps of Beckett "whose prose is poised unsettlingly between realism and anti-realism" 21 to "emphasize the wider meaning of what it means ... to write 'after Beckett'", 22

John Maxwell Coetzee is convinced that he is " not a herald of community or anything else ... [He is $\}$ someone who has intimations of freedom (as every chained prisoner has) and constructs representations - which are shadows themselves - of people slipping their chains and turning their faces to the light. [Coetzee does] not imagine freedom, freedom an sich; [He does] not represent it. Freedom is another name of the unimaginable, says Kant, and he is right" (DP, p. 341). It is for this reason that J.M Coetzee expresses his dissatisfaction with the nature of the mainstream illusionist modes of writing in the South African context because writing "should be understood in the broadest terms as an attempt to move beyond a long discursive tradition - one that includes certain powerful and enduring constructions of the form of the novel-which attempts to position literary value, or literary truth, or most generally 'culture', as superior to, or even transcendent of, politics". ${ }^{23}$

Relying on the availably accessed body of literary criticism that has dealt with J.M Coetzee, I contend that almost all critical approaches are, to a great extent, couched in their narrow-minded ideologies with the aim of approaching certain Coetzean narratives from behind the walls of their supposedly holistic, absolutist, and totalitarian theoretical confinements. Each theoretical ideational camp implicitly or overtly claims a certain kind of "truthfulness" and legitimacy to interpret a literary text according to their system of beliefs. Of course, literary criticism schools struggle to provide a world view of literature that corresponds to the basics of their philosophies. But this does not legitimize the exclusion of party over the other or the alliance of other parties over other with the aim of possessing power. It is an ongoing fight over power keys through the production of a body of knowledge that would tyrannically govern other types of knowledge. This might be also regarded, if we see the side of the fence, as something positive because of the competitiveness to come up with theories and views never experienced before. The literary text, instead of being a field of experimentation of the truthfulness of a literary discourse over the other, it however, becomes a source of challenge and inspiration for critics to innovate new tools for the assessment of a

\footnotetext{
19 Ibid., p. 15.

20 Ibid., p. 225.

21 Ibid., p.40.

22 Ibid., p. 2.

23 Ibid., p. 3.
} 
literary production. Still, by end of the experimentation, the newly created criticisms would be exposed to their own limitations and flaws.

I think that a better ground for approaching the writings of Coetzee as well as the writings of any other novelist can be found in the unmediated experience of reading and responding to the text itself. To succumb to any other schematizing or ideologically biased reading would not do any kind of justice to the written text which by its nature will eventually defy hermeneutic tropes of reading. Almost all the prevailing categorizing systems of literary theory be them politics, history, psychoanalysis, Marxism, linguistically oriented approaches, or other simplistic conventional critical analyses channel and affect the reader's interpretation of the literary artifact. In other words, it is the reader's ethical responsibility, and not just the writer's as Attridge argues for, to consider the novel as an everlastingly born anew piece of art in every time the act of reading happens. Attridge writes in The Singularity of Literature that "[to] read a work responsibly, then, is to read it without placing over it a grid of possible uses, as historical evidence, moral lesson, path to truth, political inspiration, or personal encouragement. It is to trust in the unpredictability of reading, its openness to the future." ${ }^{24}$ It is, in fact, the same unpredictability that marks the dense singularity of a black hole somewhere in the universe.

As writing is becoming, and as it is a singular event, reading is also a singular event. It is a happening and it is an immediate response to the text. Novels by Coetzee do sometimes possess their own tools of their own criticism. They are, as might be noticed, intrinsically ficto-critical works of art or works of fiction wrapped in criticism or the way around whereby fiction unfurls its poetics but is also disguised as criticism. The text becomes a two-facet coin or as a viper's lethal poison that, weirdly enough, contains its antidote serum. The ethicopolitical approaches should revise themselves and delimit their interference within any conniving engagement with the text. This would help the readers and the critical community to reconsider the artistic qualities of some writers and give credit to the fundamental aspects of their inventiveness and singularity, and to ultimately "experience Being". Rethinking the craft of writing and the reconstitution of their works in literary history has become the new pursuit of modern writers; and Coetzee is by far among the most articulate about the problematics of writing as a craft and as an aesthetic human production. Coetzee has managed to foreground his own conception of literature as a "responsible" aesthetically ethical expression of social and historical realities like the ones taking place in South Africa.

The paradoxes and ambiguities underlying his fictional body are undoubtedly fed by his preoccupations with both modern and postmodern modes of writing and informed also by his understanding of the body of criticism in which such modes are couched. Coetzee seems to abjure any sense to be incarcerated in any movement of thought although a close scrutiny of his production suggests his being flirting with specific existentialist post-structuralist ideas exemplified in his embracing of Kafka, Beckett, or Derrida. Coetzee states that "[however close is my word to the realities of South Africa today, the political situation remains a starting point only for my attempts to explore the more abiding themes [...] My stated conviction is that literature should never descend to the level of politics; it is rather a matter of elevating and refining politics so as to be worthy of literature." 25

If the novel "ha[s] a beginning at a singularity" in time, it does also have infinite recurrent self-manifestations in time as it flows with Time. It, thus, has no intention to cease or to stop; at each and every new manifestation at a given moment in time, this literary text signals just a kind of "closure" or as Barbara Herrnstein Smith thinks of it as "the poetic enclosure" when she explores the provocative question: How do poems end? The singularity

${ }^{24}$ Attridge, D. (2017). The Singularity of Literature. Taylor \& Francis, pp. 129-130.

${ }^{25}$ Kossew, S. (1996). Pen and Power: A Post-colonial Reading of JM Coetzee and André Brink (Vol. 27). Rodopi, p.19. 
of the literary text is that dense unfathomable essence that "puts [the text] to the test of its own limits" as Derrida sees it. According to Attridge, who is manifestly attached to Derrida's views of the world, "Derrida's work over the past thirty-five years constitutes the most significant, far-reaching, and inventive exploration of the importance of literature of our time."26

Derek Attridge's attachment and defense of ethics emanates from his understanding of the Levanisian philosophy of "otherness" or "alterity" in its peculiar sense. However, the ethical engagement that the literary text requires does not lie in the reader's identification with "its characters or its plot, with the human intercourse and judgments it portrays, with its depictions of virtues and vices or of the difficulty of separating these." ${ }^{27}$ Rather, the ethical attachment lies "in what makes it literature: its staging of the fundamental processes whereby language works upon us and upon the world." Literature "for all the force which it is capable of exercising, can achieve nothing without readers - responsible readers." Here, Attridge is unwaveringly positive that the ethical act of reading constitutes the core of singularity; the singularity of literature. This is why it is ethically important for the reader to respond to J.M Coetzee's fiction with a certain degree of singularity that sees of "truth" something of less a totalizing answer or solution.

\section{CONCLUSION}

J.M Coetzee's conception of literature and the craft of writing tell us that a novel's singularity has to do with its formal execution much more than its unique innovation. Singularity is indicative of the extent to which the author has managed to solve formal execution in his work. Literature as a significant cultural institution and as a peculiarly challenging form of writing, with inescapable consequences for our thinking about philosophy, politics and ethics is what pushes Derrida to define the singularity of a work as what "enables it to be repeated over and over in events that are never exactly the same." 28 Against the traditional view of the text's uniqueness, Derrida "never claims to offer a reading of a text as an organic or self-contained whole but instead to write "a text which, in the face of the event of another's text, tries to 'respond' or to 'countersign" "29 However, the reader is one who should try to "respond with writing that is rich enough and singular enough to provoke responses in its turn - not an easy matter, of course" 30 . Derrida writes "the only worthwhile kind, implies an act, a literary signature or countersignature, an inventive experience of language." 31

To sum it up, the idea of the novel as a black hole would culminate in the idea that it is beyond the ethical dimensions that the "density" of the singularity of the literary text is constituted. Just as his conception of the existential experience of being itself that Jacques Derrida pays an eloquent homage to literature because "[it] perhaps stands on the edge of everything, almost beyond everything, including itself. It's the most interesting thing in the world, maybe more interesting than the world, and this is why, if it has no definition, what is heralded and refused under the name of literature cannot be identified with any other discourse. It will never be scientific, philosophical, conversational." ${ }^{\text {"2 }}$

${ }^{26}$ Attridge, D. (2017). The Singularity of Literature. Taylor \& Francis, p. 139.

27 Ibid., p. 130.

${ }^{28}$ Caputi, M., \& Del Casino Jr, V. J. (Eds.). (2013). Derrida and the Future of the Liberal Arts:

Professions of Faith. A\&C Black, p. 83.

${ }^{29}$ Ibid., p. 83.

${ }^{30}$ Ibid., p. 84.

${ }^{31}$ Ibid., p. 84.

${ }^{32}$ Derrida, J., \& Attridge, D. (1992). Acts of literature. Routledge, p. 47. 


\section{REFERENCES}

Attridge, D. (2017). The Singularity of Literature. Taylor \& Francis.

Attwell, D. (1993). JM Coetzee: South Africa and the Politics of Writing (No. 48). Univ of California Press.

Blundell, K. (2015). Black Holes: A Very Short Introduction. Oxford University Press.

Brink, A. (1998). The Novel: Language and Narrative from Cervantes to Calvino. Macmillan International Higher Education.

Brink, A. (2011). Dry White Season. Random House.

Caputi, M., \& Del Casino Jr, V. J. (Eds.). (2013). Derrida and the Future of the Liberal Arts: Professions of Faith. A\&C Black.

Coetzee, J. M. (1980). “Grubbing for the Ideological Implications: A Clash (More or Less) with JM Coetzee.” Interview by Alan Thorold and Richard Wicksteed.

Derrida, J., \& Attridge, D. (1992). Acts of literature. Routledge.

Dovey, T. (1998). JM Coetzee: Writing in the Middle Voice. Critical Essays on JM Coetzee, 18-28.

Frolov, V., \& Novikov, I. (2012). Black Hole Physics: Basic Concepts and New Developments (Vol. 96). Springer Science \& Business Media.

Hawking, S. W. (1993). Hawking on the Big Bang and Black Holes (Vol. 8). World Scientific.

Hayes, P. (2010). JM Coetzee and the Novel: Writing and Politics After Beckett. Oxford University Press.

Huggan, G., \& Watson, S. (Eds.). (1996). Critical Perspectives on JM Coetzee. Springer.

Kossew, S. (1996). Pen and Power: A Post-colonial Reading of JM Coetzee and André Brink (Vol. 27). Rodopi.

Maran, S. P. (2017). Astronomy for Dummies. John Wiley \& Sons.

Prakash, N. (2003). Mathematical Perspectives on Theoretical Physics: A Journey from

Black Holes to Superstrings. World Scientific Publishing Company.

\section{$\underline{\text { AUTHOR'S BIO }}$}

Nabit ELGARHI is an administrator and an adjunct English language teacher at the Higher School of Technology, Laayoune, Ibn Zohr University in Morocco. He received his MA in Postcolonial Studies within the program of Race, Ethnicity and Alterity in Literature and Culture, Ibn Zohr University in Morocco (2007), and currently finishing his PhD in Postcolonial Studies dealing with the works of the South African writer J.M Coetzee. 